\title{
La pintura mural del siglo XV en Valladolid: Iglesia parroquial de Fresno el Viejo
}

\author{
Sergio NúÑEZ MoRCILLO \\ Departamento de Historia del Arte de la Universidad de Valladolid.
}

\begin{abstract}
RESUMEN
La iglesia de San Juan Bautista de Fresno el Viejo, situada al sur de la provincia de Valladolid, cuenta con un magnífico conjunto mural tardogótico descubierto recientemente en el contexto de la restauración del edificio. Éste, se extiende por el ábside central del templo. En este sentido, en el hemiciclo absidal se representan escenas relativas a la vida de San Juan Bautista; en la bóveda de horno la Maiestas Domini rodeada de los símbolos de los cuatro Evangelistas (Tetramorfos) y los ángeles con las Arma Christi y en el arco de separación del cascarón absidal y del tramo recto absidal, figuras humanas, quizás profetas, rodeadas de diversos motivos decorativos.
\end{abstract}

Palabras clave: Fresno el Viejo; Hospitalarios; Pintura mural; Tardogótico; San Juan Bautista.

\section{The fifteenth century mural painting in Valladolid: Parish church of Fresno el Viejo}

\begin{abstract}
The church of San Juan Bautista of Fresno el Viejo, located in the south of the province of Valladolid, has a magnificent mural painting of the late Gothic period recently discovered in the context of the restoration of the building. This covers from the central apse of the church. In this regard, in the wall of the apse are depicted scenes relating to the life of St. John the Baptist, in the vault of the apse the Maiestas Domini surrounded by the symbols of the four Evangelists (Tetramorph) and the angels with the Arma Christi and in the arch separating the vault of the apse and the presbitery, human figures, perhaps prophets, surrounded by various decorative motifs.
\end{abstract}

Keywords: Fresno el Viejo; Hospitallers; Wall Painting; Late Gothic; St. John the Baptist.

\section{Introducción}

El estudio pormenorizado de las pinturas murales tardogóticas de la iglesia de San Juan Bautista de Fresno el Viejo se justifica por varias circunstancias, siendo especialmente necesario reseñar dos de ellas: por un lado, la de dar a conocer la existencia de pintura mural tardogótica en este ámbito de Castilla y León (donde esta modalidad pictórica es menos conocida que en otras zonas de la comunidad, como el norte de Palencia y de Burgos, estudiadas por Santiago Manzarbeitia Valle 
y por Aurelio Barrón García) y, por otro lado, llamar la atención ante los constantes descubrimientos que se están produciendo en la actualidad en el contexto de las restauraciones de templos religiosos.

\section{Fresno el Viejo. Una villa Sanjuanista}

La localidad de Fresno el Viejo se encuentra situada al sur de la provincia de Valladolid, limitando con las provincias de Salamanca y Ávila y más concretamente a ambos lados de la Calzada Real que une Salamanca con Medina del Campo.

La historia de la villa de Fresno el Viejo está íntimamente relacionada con la Orden del Hospital de San Juan de Jerusalén. En sus inicios, la citada Orden, tuvo una función exclusivamente asistencial dedicándose al cuidado de los enfermos y peregrinos que acudían a Tierra Santa, pero las crecientes necesidades defensivas de los reinos y principados cruzados propiciaron su inminente militarización, llegando a asentarse en la Península antes del citado proceso. Durante los primeros años en territorio peninsular, la institución no sólo tuvo un carácter asistencial sino también una impronta militar, hecho que llevó a los freires sanjuanistas a participar en el proceso de reconquista y a repoblar territorios.

Esta situación explicaría que a lo largo del siglo XII, mediante un proceso de donaciones reales protagonizadas por la reina doña Urraca y por su hijo Alfonso VII entre 1113 y 1170 , se vaya aglutinando bajo la dirección de la Orden un vasto territorio en la zona sudoriental de la actual provincia de Zamora, territorio recorrido por el río Guareña, lo cual dará lugar a un espacio geopolítico conocido como encomiendas de Valdeguareña ${ }^{1}$. Dentro de este proceso, para nuestro estudio será de espacial interés el 11 de noviembre de 1116, momento en el que doña Urraca entrega a Frey Pelagio Arúlfiz y Frey Juan Sebastián, representantes de la Orden del Hospital de San Juan de Jerusalén, la localidad de Fresno el Viejo².

\section{Iglesia de San Juan Bautista}

En el momento en que se produjo la donación, Fresno el Viejo, con toda probabilidad, no contaba con un edificio religioso en condiciones ${ }^{3}$, máxime teniendo en cuenta la importancia que para la orden tenía la liturgia ${ }^{4}$. En este sentido, fue

1 OJEDA NIETO, José, Comendadores y vasallos (La Orden de San Juan y el partido de Valdeguareña), Salamanca, Instituto de Estudios Zamoranos, Diputación de Zamora, 1997, p. 23.

2 PÉREZ MONZÓN, Olga, Arte Sanjuanista en Castilla y León. Las encomiendas de la Guareña y su entorno geo-histórico, Valladolid, Junta de Castilla y León, 1999, p. 119.

3 Idem, p. 123.

4 BARQUERO GOÑI, Carlos, Los caballeros hospitalarios durante la Edad Media en España (siglos $X I I-X V)$, Burgos, Editorial La Olmeda, 2003, p. 150. 
esencial la carta de donación efectuada por la reina Urraca el 11 de noviembre de 1117 , en la que la orden adquirió la responsabilidad de alzar un edificio religioso adecuado a sus necesidades ${ }^{5}$.

Además, un documento fechado en Medina del Campo el 23 de diciembre de 1121, dirigido al obispo de Salamanca, Jerónimo, indica que la aldea de Fresno el Viejo había sido entregada a la orden hospitalaria a fin de que éstos, edificasen cuanto antes su templo y su morada ${ }^{6}$.

Si bien apenas existen dudas referidas al origen del templo, sí que las hay sobre la fecha en la que la fábrica del edificio fue terminada o sobre la razón por la que comenzándose a construir en piedra, material utilizado para la cimentación, las paredes de la cabecera y los capiteles que marcan la entrada de los ábsides, éste se terminó en ladrillo, pues a la altura de los arcos torales se dio paso a un estilo mudéjar. Aunque la sustitución de la piedra por el ladrillo pudo haberse debido a problemas económicos, quizás relacionados, como indica Olga Pérez Monzón, con la interrupción de las obras del templo fruto de la guerra que enfrentó a Castilla y a León en la segunda mitad del siglo XII (comenzó en 1157)7, según José María Azcárate Ristori, en la utilización del ladrillo no tiene por qué intervenir ningún acontecimiento, sino que la necesidad de realizar rápidamente un templo provoca el uso de materiales forzosamente pobres, tanto por la escasez de medios económicos como por el carácter utilitario que generalmente adquieren estas construcciones ${ }^{8}$.

Con todo, la cabecera tripartita o la planta basilical de tres naves, manifiesta un esquema y un planteamiento acorde con un edificio de estilo románico9.

En mi opinión, la interrupción de la construcción se produjo con motivo de las guerras del siglo XII entre Castilla y León, lo cual provocaría una modificación de los planes constructivos. Así, cuando se reanudaron las obras se cambió de material utilizándose elementos y formas que, según Borrás Gualis ${ }^{10}$, son plenamente mudéjares, visibles en la organización de las fachadas, el empleo de ladrillo o el empleo de la madera para la cubierta del coro.

AYALA MARTÍNEZ, Carlos de, Libro de privilegios de la orden de San Juan de Jerusalén en Castilla y León (siglos XII-XV), Madrid, Instituto Complutense de Estudios de la Orden de Malta, 1995, doc. $\mathrm{n}^{\circ} 11$, pp. 153-154.

6 GONZÁLEZ SÁNCHEZ, Vidal, Fresno el Viejo: una encomienda sanjuanista en la frontera de dos reinos, Valladolid, Ayuntamiento de Fresno el Viejo, 2002, p. 64, n. 25.

7 PÉREZ MONZÓN, Olga (1999), op. cit., p. 124.

8 AZCÁRATE RISTORI, José María, "Las órdenes militares y el arte", en VV.AA., Actas del simposio el Arte y las Órdenes militares, Cáceres, 1985, p. 30.

9 PÉREZ MONZÓN, Olga (1999), op. cit., p. 123.

10 BORRÁS GUALIS, Gonzalo M., El arte mudéjar, Madrid, Instituto de Estudios Turolenses, 1990. 


\section{Estudio sobre las pinturas murales}

En la iglesia de San Juan Bautista de Fresno el Viejo, con ocasión de las obras de restauración del edificio terminadas en 2003, se descubrieron en su interior varios conjuntos de pinturas murales, las cuales fueron limpiadas, consolidadas y restauradas para su posterior puesta en valor. Las que me interesan en el contexto del presente trabajo se encuentran en la capilla mayor de la iglesia, concretamente en el hemiciclo, en el cuarto de esfera absidal y en el arco de separación entre la bóveda de cascarón y el tramo recto absidal (fig. 1). Mientras que las

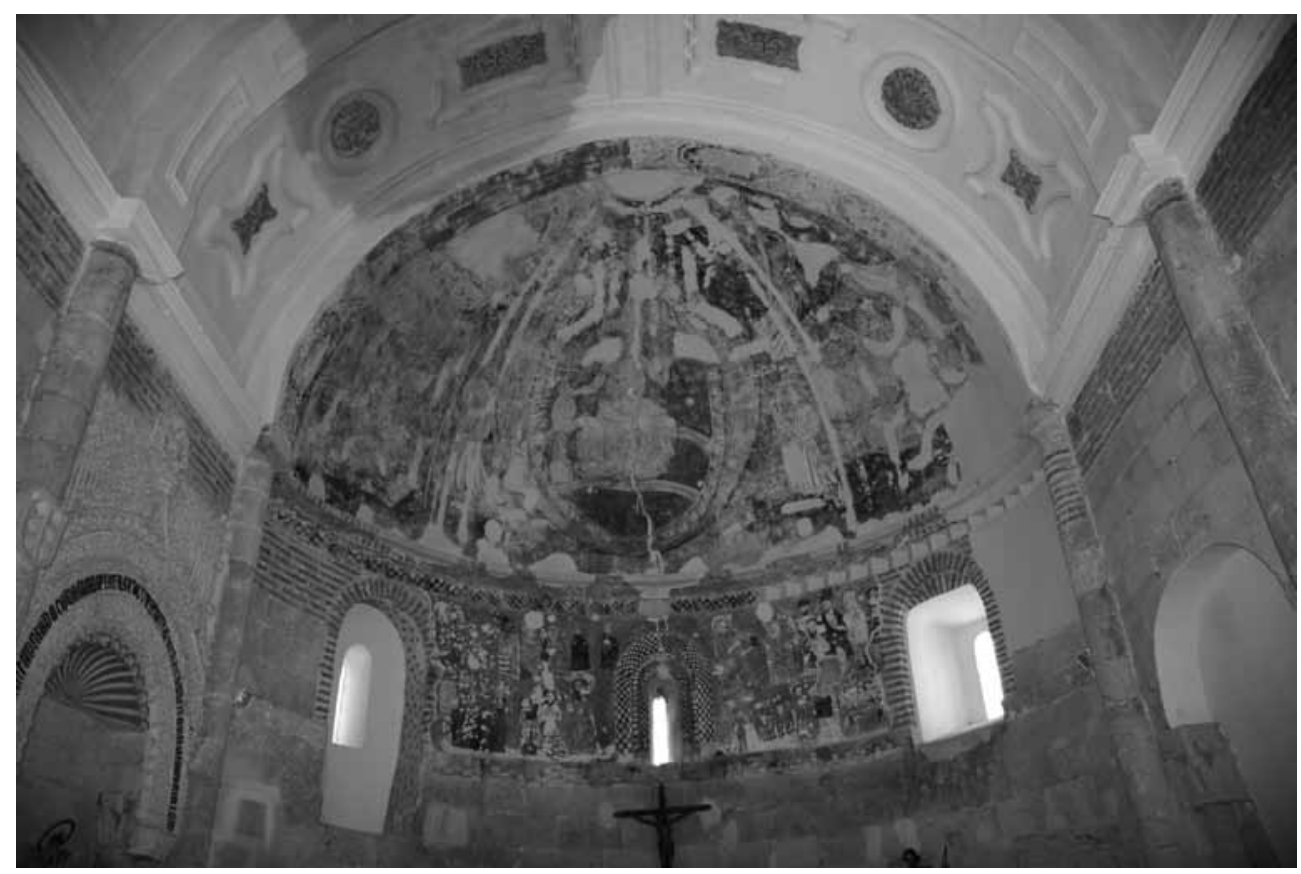

Fig. 1. Conjunto mural, siglo XV, pintura al temple, iglesia de San Juan Bautista, Fresno el Viejo (Valladolid).

correspondientes al hemiciclo absidal aparecieron detrás de una capa de cal tras efectuarse el desmontaje de un retablo de estilo Neoclásico (fig. 2), las de la bóveda de horno y el arco de separación, se localizaron detrás una decoración de yeserías barrocas.

\section{Hemiciclo absidal}

En él se sitúa un conjunto mural en el que se narra la vida de San Juan Bautista, titular del templo y de la orden. Ubicado entre una línea de imposta de taqueado jaqués, en la parte inferior y un friso de ladrillo en esquinilla ornamentado por medio de una decoración a base de ajedrezado, en la parte superior, dicho conjunto 


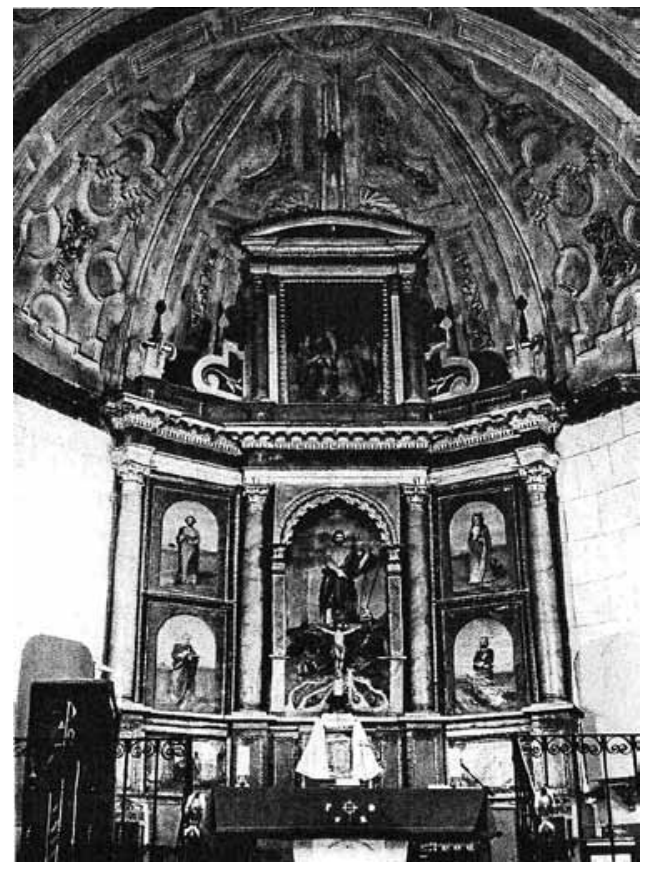

Fig. 2. Iglesia de San Juan Bautista, Fresno el Viejo (Valladolid), vista del ábside central antes de la restauración [tomado de GONZÁLEZ SÁNCHEZ, Vidal, Fresno el Viejo: una encomienda sanjuanista en la frontera de dos reinos, Valladolid, Ayuntamiento de Fresno el Viejo, 2002, p. 306]. está limitado por dos vanos, uno en el lado del Evangelio y otro en el lado de la Epístola.

Junto a esta delimitación, las siete escenas que subsisten, las cuales se superponen y se suceden por medio de una mera yuxtaposición, renunciando a cualquier tipo de compartimentación, se encuentran separadas por medio de un vano central, cuyo extradós también se encuentra ornamentado por medio de motivos de ajedrezado (fig. 3).

En ese sentido y, siguiendo el orden de lectura correcto (de izquierda a derecha), comenzaré a analizar los pasajes emplazados entre el vano del lado del Evangelio y el central.

En primer lugar, me voy a referir al episodio de la Visitación representado en el registro superior de la parte izquierda. La composición muestra, de manera sencilla, el encuentro entre Santa Isabel, con la cabeza y cuello cubiertos con una toca, a la izquierda, y la Virgen María identificada con un nimbo de color rojo,

alusivo a su santidad, a la derecha. Con la intención de mostrar su condición de gravidez, ambas visten sayas y mantos holgados en la zona del vientre y no aparecen fundidas en un abrazo cercano y profundo, sino que muestran más bien una actitud distante y contenida ${ }^{11}$.

Por debajo de este pasaje se desarrolla el episodio del Nacimiento de San Juan Bautista. Santa Isabel tumbada en la cama, está acompañada por la Virgen María que, ataviada de la misma forma que en la Visitación, sostiene al recién nacido ${ }^{12}$. Acompañando a las dos mujeres protagonistas, tenemos dos doncellas. Quizá, las más interesante, por lo que lleva en la mano derecha, es la más próxima a la cabecera de la cama donde yace Santa Isabel. Ésta porta una bandeja en la que con dificultad se pueden apreciar pequeñas formas circulares. Si se atiende al estudio realizado por Pilar Silva Maroto sobre el Retablo del Bautismo de Juan de Flandes

11 GUTIÉRREZ BAÑOS, Fernando, "Pinturas murales medievales en San Esteban de Gormaz”, en Celtiberia, $\mathrm{n}^{\circ} 102,2008$, p. 52.

12 VORÁGINE, Santiago de la, La Leyenda Dorada, t. 1, Madrid, Alianza Editorial, 1984, p. 337. 


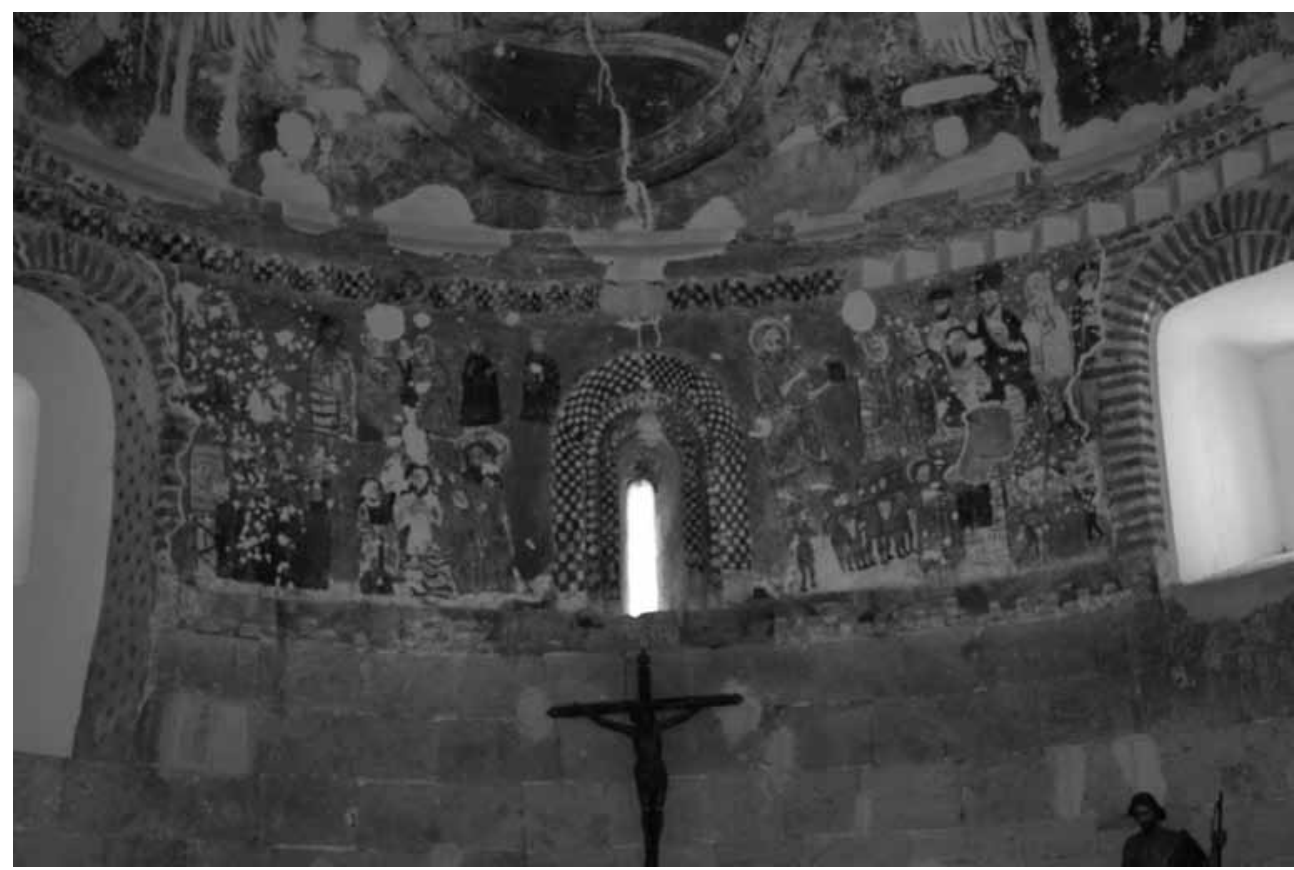

Fig. 3. Escenas de la vida de San Juan Bautista, siglo XV, pintura al temple, iglesia de San Juan Bautista, Fresno el Viejo (Valladolid).

para la Cartuja de Miraflores, éstas pudieran ser cerezas ${ }^{13}$, pues como indica Federico Revilla, son anunciadoras de la prosperidad, de la abundancia y de la felicidad material ${ }^{14}$, por lo que podrían ser una metáfora del carácter de San Juan Bautista como Precursor de Cristo, quien traerá una nueva vida.

A la derecha de la escena de la Visitación se sitúa la Imposición del nombre al Bautista. A la izquierda, se representa a Zacarías quien, tras haber perdido la voz ante la incredulidad mostrada hacia el designio divino que le indicaba que tendría un hijo llamado Juan ${ }^{15}$, sentado y con un bonete, escribe en un trozo de papel: Ioanes voca/bitur ${ }^{16}$. A su izquierda y, de forma poco habitual, siguiendo, con toda probabilidad el pasaje de La Leyenda Dorada de Santiago de la Vorágine ${ }^{17}$, está la Virgen María sosteniendo el niño, cuyo atavío se corresponde con el visto en las dos escenas anteriores. A su lado, aparece una doncella y Santa Isabel con el tocado de la Visitación o la Natividad.

\footnotetext{
13 SILVA MAROTO, María Pilar, Juan de Flandes, Salamanca, Caja Duero, 2006, p. 150.

14 REVILLA, Federico, Diccionario de iconografía y simbología, Madrid, Cátedra, 1999, p. 102.

15 Lucas 1, 13 y Lucas 1, 18-20.

16 Lucas 1, 57-65.

17 VORÁGINE, Santiago de la (1984), op. cit., p. 337.
} 
A la derecha de este pasaje, se disponen dos personajes, en actitud de conversación, sobre los cuales no se tiene del todo claro su identidad. A estas dos figuras se refirió Vidal González Sánchez, quien indicó que estarían vinculadas con la composición situada a la derecha de la ventana central que identificó con el momento en el que la reina doña Urraca dona la localidad de Fresno el Viejo a la Orden. Por ello, estas dos figuras, serían, según González Sánchez, Frey Pelagio Arúlfiz, delegado de la Orden, y Frey Juan Sebastián, prior de la parroquia que se constituirá en la villa ${ }^{18}$.

Estos dos personajes pudieran estar vinculados con el episodio de la Imposición del nombre, pues tan solo hay que ver la disposición que ocupan dentro del conjunto mural. Además, su atuendo, una loba talar negra, y su tocado, indicarían su vínculo con el Templo, lugar donde se está produciendo el acontecimiento.

A la derecha de la escena de la Natividad del Bautista y debajo de la de la Imposición del nombre, aparece un pasaje que si bien pudiera tratarse del episodio del Bautismo de Cristo, sería más bien, como ya indicó Javier Castán Lanaspa, el Bautismo de San Juan Bautista por Cristo ${ }^{19}$ (fig. 4).

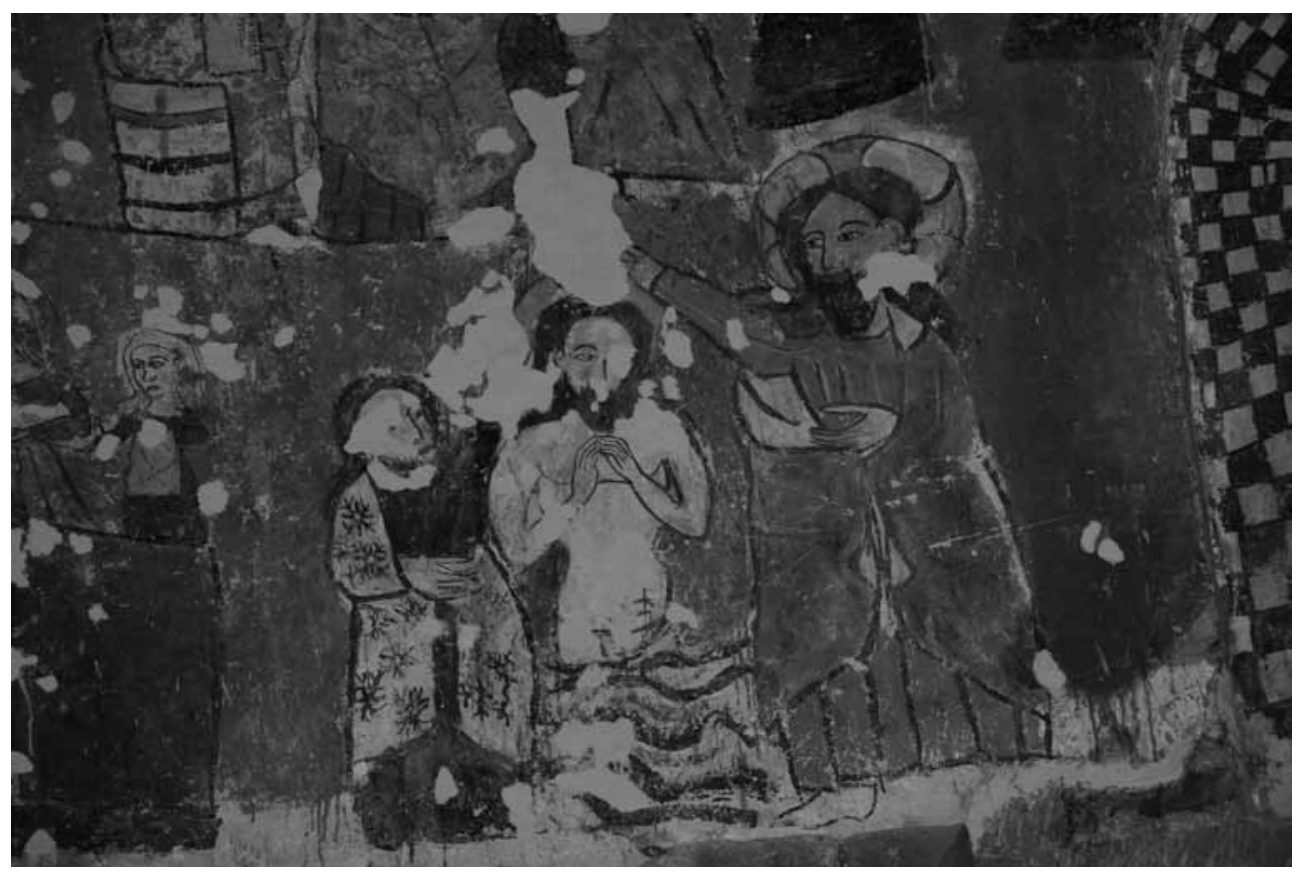

Fig. 4. Escena de El Bautismo de San Juan Bautista por Cristo, siglo XV, pintura al temple, iglesia de San Juan Bautista, Fresno el Viejo (Valladolid).

18 GONZÁLEZ SÁNCHEZ, Vidal (2002), op. cit., p. 24.

19 CASTÁN LANASPA, Javier, Catálogo monumental del antiguo partido judicial de Nava del Rey, Valladolid, Diputación de Valladolid, 2007, p. 74, n. 22. 
Efectivamente en el centro de la composición se sitúa el Precursor, el cual recibe los dos tipos de bautismo: el bautismo de inmersión, pues desnudo, las aguas del rió Jordán (representadas como ondas) le llegan hasta la cintura, y el bautismo por aspersión, en el que Cristo derrama agua sobre la cabeza del Bautista. El Mesías, a la izquierda del Bautista, se distingue por su nimbo crucífero y va ataviado con una vestimenta compuesta por una saya de color rojo cubierta por un manto gris. La figura de la derecha, aunque con más dudas, pudiera ser uno de los ángeles que con asiduidad se representa en el episodio del Bautismo de Cristo, los cuales descenderían del cielo y oficiarían como diáconos. Todo ello estaría indicando que, a pesar de ser un tema referente al Bautismo del Precursor, el autor ha recurrido a numerosos recursos del Bautismo de Cristo.

Es evidente que éste es un tema inusual, pero no debe ser entendido como un error del artista o fruto de su desconocimiento sobre los programas iconográficos, puesto que en la colegiata de Medinaceli en Soria se conserva un relieve perteneciente al siglo XVI con el mismo tema, aunque debieron existir más ejemplos ${ }^{20}$.

Probablemente, con este tipo de representación, no sólo se pretendía que el Mesías se convirtiera en un elemento activo, sino que como núcleo sanjuanista, se buscaba reafirmar el patronazgo del Bautista, resaltando su figura mediante el bautismo, e indicar que el Bautismo ejercido por el Precursor no es la verdadera fuente de salvación, sino que lo es Cristo y, por ende, el Bautismo de la Iglesia: "Entonces Jesús fue de Galilea al Jordán para que Juan lo bautizara. Pero Juan quería impedirlo, diciendo: "Soy yo el que necesita ser bautizado por ti, ¿y tú vienes a mí?” Jesús le respondió: "¡Déjame ahora, pues conviene que se cumpla así toda justicia!”21.

Entre el vano central y el del lado de la Epístola se sitúan los siguientes pasajes:

En el registro superior, aparece la Reprimenda de San Juan Bautista a Herodías. Aunque contradiciendo la interpretación realizada por Vidal González Sánchez, quien indicaba que se trataba del momento en el que la reina doña Urraca dona la localidad de Fresno el Viejo a la orden, la interpretación que se da aquí, ya indicada por Javier Castán Lanaspa con anterioridad ${ }^{22}$, se fundamenta en la devoción existente en el medievo donde se reservan grandes espacios en los templos a la vida de los santos para que el fiel se sintiera cercano a ellos y los conociera, advirtiéndose un fin catequético y didáctico al pretender que el creyente comprenda con claridad lo que está representado. Por ello, intercalar un pasaje sobre un acontecimiento local, resultaría confuso para las personas, en las que no hay que olvidar el elevado grado de analfabetismo existente.

${ }^{20}$ CORTÉS ARRESE, Miguel, “104. Cristo bautizando a San Juan”, en La ciudad de seis pisos, catálogo de la exposición (Burgo de Osma, 1997), Burgo de Osma, Fundación las Edades del Hombre, 1997, pp. 205206.

${ }^{21}$ Mateo 3, 13-15.

22 CASTÁN LANASPA, Javier (2007), op. cit., p. 74. 
Esta episodio no ha sido representada de la forma habitual pues mientras que en el ciclo iconográfico relativo a la vida del Precursor el pasaje narra el momento en que San Juan Bautista tiene la valentía de reprochar a Herodes su matrimonio con Herodías, ya que ésta era la mujer de su hermano Filipo, en esta ocasión es Herodías y no Herodes quien recibe de parte de San Juan Bautista, a la izquierda y vestido con el sayo de pelo de camello, la recriminación por su unión ilícita.

Como consecuencia del episodio anterior, se representa el Prendimiento y el Encarcelamiento de San Juan Bautista en una de las torres de la fortaleza de Herodes en Maqueronte ${ }^{23}$. Si se tiene en cuenta lo indicado por Louis Réau, el artista en este caso, a diferencia de lo visto en la escena del Bautismo del Precursor y en la de la Reprimenda de Herodías, ha plasmado el pasaje de la forma habitual: San Juan Bautista siendo llevado a la cárcel, generalmente representada de forma cilíndrica y almenada.

Por último, para terminar con el ciclo de la vida de San Juan Bautista, es necesario analizar el pasaje dedicado al Banquete de Herodes y la danza de Salomé. Según la leyenda, Herodes, tras observar el baile realizado por su hijastra Salomé ante él, le prometió satisfacer cualquier deseo que ella quisiese. Salomé, de acuerdo con la promesa que había hecho a su madre Herodías, que quería vengarse de San Juan Bautista, pidió a Herodes la cabeza del Precursor ${ }^{24}$.

Esta escena, en las pinturas murales de Fresno el Viejo, aparece de la forma habitual, es decir, Herodes presidiendo la mesa del banquete, tocado con una corona, sentado junto a su mujer. Delante de la mesa Salomé aparece danzando, entreteniendo a los comensales, tocando un instrumento de cuerda. Al lado de Salomé, aparece el característico sirviente disponiendo los diferentes utensilios sobre la mesa.

Interesante es la manera en que el artista ha representado la mesa, pues está repleta de viandas, quizá un pan y dos peces, alimentos típicos de la iconografía de la Santa Cena, por lo que podemos decir, que asistimos a un ejemplo de contaminación iconográfica. Quizás, al igual que con la escena del Bautismo de San Juan Bautista por Cristo, el artista intentase recalcar la figura del Mesías, en la que el pan y el pescado, podrían adquirir un sentido claramente eucarístico.

Tras el estudio del conjunto mural emplazado en el hemiciclo absidal y, especialmente tras haber analizado la escena anterior, parece ser, aunque no hay ninguna constancia de su presencia, que faltan algunas de las escenas del programa iconográfico de San Juan Bautista tales como la Decapitación o el Entierro por parte de los discípulos. Probablemente, si es que existieron, éstas estuvieron localizadas tanto a la izquierda del vano del lado del Evangelio como a la derecha del vano del lado de la Epístola.

23 RÉAU, Louis, Iconografia del arte cristiano. Iconografía de la Biblia. Antiguo Testamento, t. 1, vol. 1, Barcelona, Ediciones del Serbal, 1996, p. 510.

24 Mateo 14, 6-8. 


\section{El cuarto de esfera absidal}

En este ámbito y sobre un fondo cubierto de estrellas blancas y con el sol y la luna representados en la parte superior, se ubica la Maiestas Domini rodeada por el Tetramorfos y por ángeles que portan los instrumentos de la Pasión o Arma Christi (fig. 5).

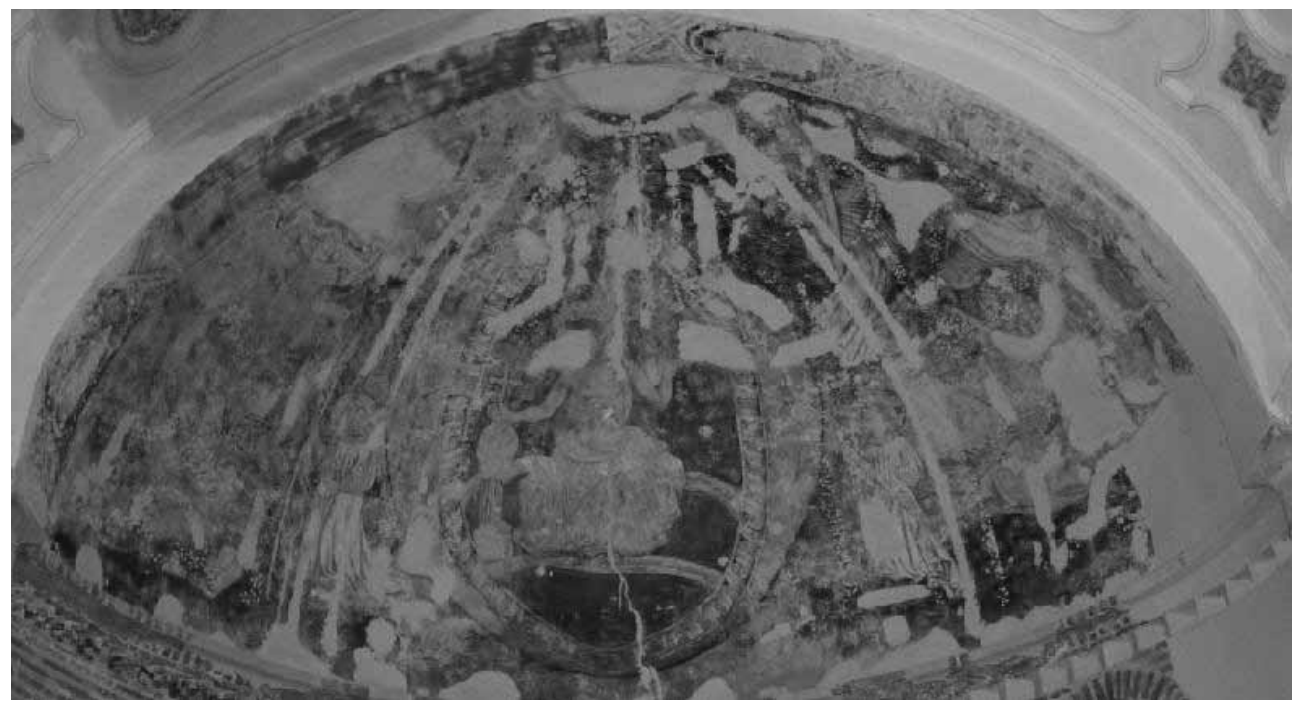

Fig. 5. Representación de La Maiestas Domini, el Tetramórfos y los ángeles con las Arma Christi, siglo XV, pintura al temple, iglesia de San Juan Bautista, Fresno el Viejo (Valladolid).

La figura de Cristo en Majestad ocupa, como es obvio, el lugar preferente de la composición, afectado por una serie de lagunas que dificultan su visión. Cristo aparece sentado, con el torso desnudo mostrando la llaga del costado y el brazo izquierdo levantado, con la mano abierta, enseñando las llagas de la crucifixión. Con la mano derecha agarra una cruz, la cual emerge de un orbe, que a su vez descansa sobre una columna.

Cristo sentado sobre dos arco iris y rodeado por la tradicional mandorla se presenta estrechamente escoltado por ángeles alados llevando los siguientes instrumentos de la pasión: arriba, a la derecha, la cruz; abajo, a la derecha, la columna; abajo, a la izquierda, la lanza y los clavos; arriba, a la izquierda, con toda probabilidad y basándome en lo que suele aparecer representado en otras ocasiones, la corona de espinas.

Junto a los ángeles, flanqueando la Maiestas Domini, están los símbolos de los evangelistas alados y en muy mal estado de conservación: arriba, a la derecha, el hombre de San Mateo; abajo, a la derecha, el toro de San Lucas; abajo, a la izquierda, el león de San Marcos; arriba, a la izquierda, el águila de San Juan. 
El presente programa iconográfico responde, aunque de forma sintética, al Juicio final. La figura de Cristo en Majestad no tiene que ver con el Cristo Apocalíptico del románico, imperturbable, justiciero, sino más bien con un Cristo Redentor, humanizado ${ }^{25}$, entendido como el Hijo del Hombre, el cual enseña los signos de su sacrificio: las llagas son muestra de su sufrimiento por la salvación de la humanidad, convirtiéndose en testimonio de su triunfo sobre la muerte.

Los elementos con los que está rodeado corroborarían la temática indicada: Cristo aparece sentado sobre dos arco iris. Si bien la presencia de este elemento es habitual en los episodios dedicados al Juicio final, no lo es el que se representen dos, los cuales harían referencia, al Antiguo y al Nuevo Testamento ${ }^{26}$. El arco iris se relaciona con el simbólico pacto establecido por Dios y Noé tras el diluvio ${ }^{27}$.

La disposición del orbe sobre la columna al lado derecho de Cristo indicaría que Dios es el único que tiene el poder de derribar las columnas que sostienen el mundo el día del Juicio final ${ }^{28}$. Por el contrario, la cruz que se sitúa sobre el orbe simbolizaría cómo por medio del sufrimiento de Cristo en la cruz, el hombre alcanza la redención y la salvación.

Los ángeles llevando las Arma Christi estarían relacionados con este último aspecto, pues con éstas garantizarían que todo el mundo fuera consciente de la victoria del Redentor, irradiando los instrumentos una luz que eclipsaría tanto el sol como la luna ${ }^{29}$. El Evangelio de San Mateo también hace referencia a este pasaje ${ }^{30}$.

\section{Arco de separación entre la bóveda de cascarón y el tramo recto absidal.}

Se disponen una serie de efigies, probablemente profetas, cuyo mal estado de conservación imposibilita realizar una identificación segura. El arco se organiza a partir de líneas paralelas, las cuales se entrecruzan definiendo los compartimentos hexagonales donde se ubican los profetas y encasamentos cuadrangulares en cuyo interior se dispone una forma geométrica de rombo: el losange o losanje, donde se sitúa el emblema de la orden del Hospital de San Juan de Jerusalén, más tarde, orden de Malta: la cruz de Malta.

Aprovechando los flancos de cada uno de los citados losanges, se disponen, utilizando una gama de grises, una serie de formas triangulares, parecidas a las de la

25 PANERA CUEVAS, Francisco Javier, El retablo de la catedral vieja y la pintura gótica internacional en Salamanca, Salamanca, Centro de Estudios Salmantinos, 1995, pp. 170-171.

26 RÉAU, Louis (1996), op. cit, p. 757.

27 CARMONA MUELA, Juan, Iconografia cristiana, Madrid, Akal, 2008, p. 157.

28 BIEDERMANN, Hans, Diccionario de símbolos, Barcelona, Paidós, 1993, p. 118.

29 MÂLE, Émile, El gótico. La iconografia de la Edad Media y sus fuentes, Madrid, Encuentro, 1986, p. 359 .

30 Mateo 24, 30 . 
bóveda del presbiterio de la iglesia de San Cornelio y San Cipriano en San Cebrián de Mudá (Palencia) ${ }^{31}$.

Si bien esta semejanza podría llevar a pensar que se trata de motivos ornamentales desarrollados con asiduidad durante el periodo tardogótico, la manera con la que el pintor de la iglesia de Fresno el Viejo ha llevado a cabo el tratamiento del espacio situado entre los supuestos profetas, podría recordar a la forma de resolver el espacio entre los bustos de los personajes del Antiguo Testamento en las cenefas que dan acceso al cascarón absidal de la catedral vieja de Salamanca, donde, por obra de Nicolás Florentino, se representa el tema del Juicio final.

Las tres figuras que se conservan, aunque con toda probabilidad debieron de ser seis, están en bastante buen estado, individualizadas por su caracterización física y por las diferentes tonalidades que adquieren sus vestimentas. De las tres que se conservan, una de ellas está barbada, mientras que las otras, aunque sus rostros prácticamente han desparecido, parecen imberbes. Una de ellas, porta un libro entre sus manos, pero no se sabe si el resto también lo llevaría. Además, cada uno de los profetas va acompañado con una filacteria en la que aparecería inscrito su nombre o, quizás, algún pasaje de sus profecías.

\section{Referentes cronológicos}

Para determinar de la manera más precisa posible la cronología de las pinturas murales situadas en el hemiciclo absidal puede resultar especialmente útil el análisis de la indumentaria con la que van ataviadas las figuras que componen las escenas situadas entre el vano central y el del lado de la Epístola, por corresponder a personajes de elevada condición social cuya indumentaria se ajusta a la evolución de la moda y por encontrarse en un aceptable estado de conservación.

Comenzando con la escena de la Reprimenda del Bautista a Herodías, aunque Herodías y Salomé van vestidas de la misma manera, es decir con un hábito, prenda usada con asiduidad durante el siglo XV, y un manto sobre él, es de especial interés Herodías, quien lleva un hábito talar compuesto, según Carmen Bernis, por mangas "largas e angostas" ${ }^{32}$ y un manto corto rasgado en los costados, sobretodo muy estilado durante los treinta primeros años del siglo XV, el cual permitía sacar los brazos por las aberturas ${ }^{33}$. Además, sobre su cabeza luce una toca con doblez que encuadra el rostro, típica de comienzos del siglo $\mathrm{XV}^{34}$. Si bien los personajes

31 MANZARBEITIA VALLE, Santiago, La pintura medieval en torno al Alto Campoo, Palencia, Institución Tello Téllez de Meneses, Diputación de Palencia, 2001, p. 170.

32 BERNIS MADRAZO, Carmen, Trajes y modas en la España de los Reyes Católicos. Los Hombres, t. II, Madrid, Instituto Diego Velázquez (CSIC), 1979, p. 95.

33 Id., Indumentaria medieval española, Madrid, Instituto Diego Velázquez (CSIC), 1956, p. 49.

34 Ibid., p. 51. 
situados detrás de Salomé serían miembros de la corte y por lo tanto susceptibles a estudiar, el poco detallismo de las vestimentas, hace que me centre en los tocados, especialmente en el bonete del tercer personaje comenzando por la derecha, el cual se corresponde con el que se impuso entre la tercera y cuarta década del siglo XV, momento en el que estilaron los tocados de gran tamaño ${ }^{35}$.

En la escena del Prendimiento y el Encarcelamiento de San Juan Bautista, es de especial interés el armamento que llevan los soldados.

El escudo portado por tres de los seis soldados, es una adarga, de origen musulmán, por lo que su presencia extrañaría. Sin embargo, podría referirse a cada uno de los fieles cristianos amenazados por los ataques y actos promovidos por los musulmanes en Tierra Santa. No sólo se aprecia el aspecto arriñonado de este tipo de escudo, sino también la piel utilizada en la confección y las borlas del exterior, las cuales servían como elemento decorativo y de resistencia ${ }^{36}$.

El casco de los soldados se corresponde con un bacinete. El modelo más representado, aparece en cuatro combatientes, estaría compuesto por una parte superior de forma apuntada ensamblada a una pieza semicircular denominada gorjal, cubriendo toda la cabeza y la nuca a excepción de la cara. Estos bacinetes, cuya vista móvil se encuentra levantada, contrastan con el del soldado situado al lado del Bautista, pues aparece con la vista móvil sobre el rostro, lo cual hizo que a este tipo de bacinete se le llamara "cabeza de perro" ${ }^{37}$. El sexto de los combatientes, el tercero por la izquierda, también llevaría, debido al ligero apuntamiento y al camal, este tipo de yelmo, pero sin defensas corporales.

Las armaduras completas de los soldados supusieron la culminación de las piezas de arnés en el siglo $\mathrm{XV}^{38}$. Éstos van armados además de con el gorjal, con piezas de arnés en las extremidades superiores (guardabrazos) e inferiores. Además, el pecho está cubierto por el peto, mientras que la parte situada entre la cintura y la zona superior de las extremidades inferiores, estaría protegida por el faldellín.

En el pasaje dedicado al Banquete de Herodes y la danza de Salomé, Herodes va tocado con la corona y ataviado con una hopa, de acuerdo a la moda que se impuso durante el último tercio del siglo XIV y las tres primeras décadas del siglo XV, la cual se basaba en la búsqueda de contrastes, esto es, en la creación, por un lado de siluetas recortadas y, por otro, de siluetas ampulosas, subrayando algunas partes del

35 Ibid., p. 45.

36 SOLER DEL CAMPO, Álvaro, La evolución del armamento medieval en el reino castellano-leones y Al-Andalus (siglos XII-XIV), Madrid, Editorial de la Universidad Complutense, 1991, p. 301.

37 HOLMES, Richard (ed.), Arma: historia visual de armas y armaduras, Madrid, Pearson Educación, 2008, p. 87.

38 SOLER DEL CAMPO, Álvaro (1991), op. cit., pp. 430-431. 
cuerpo o borrando otras ${ }^{39}$. Salomé viste de acuerdo a la moda de la misma época, visible en el amplio escote; la tendencia a marcar la cintura; el aumento del vuelo del vestido o el desarrollo de las mangas. El laúd que tañe tiene las características que adquirió el instrumento a partir del siglo XV: contorno no piriforme, más bien almendrado. Probablemente, el mástil se configura independientemente de la caja de resonancia y, por último, destaca la disposición en ángulo del clavijero ${ }^{40}$.

El sirviente llevaría una de las prendas características del momento: la jaqueta, habitualmente llevada sobre el jubón.

\section{Conclusión: fases de la realización y caracteres estilísticos}

Los rasgos de la indumentaria, armamento e instrumentos musicales sitúan las pinturas murales del hemiciclo absidal dentro de la primera mitad del siglo XV. Además, la presencia de elementos anecdóticos en la escena del Festín de Herodes y la Danza de Salomé, y el gusto por trajes delicados y exóticos, ubican este conjunto mural en la órbita del estilo gótico internacional, si bien con un carácter un tanto marginal, patente en sus cualidades técnicas y estilísticas, así como en sus arcaísmos y vestimentas usadas a comienzos del siglo XV, pero fruto de la revolución de la moda durante el último cuarto del siglo XIV, o por la línea gruesa con que las figuras son perfiladas que recuerdan al estilo gótico lineal.

Por lo que a las pinturas murales situadas en el cascarón absidal y en el arco se refiere, su análisis es más complejo dada la inexistencia de elementos arqueológicos de referencia. El conjunto mural situado en ambos ámbitos pertenece también al siglo XV, pero, a diferencia del emplazado en el semicírculo absidal, habría sido realizado en una segunda fase, viéndose correspondencias con un gótico internacional más avanzado.

El conjunto mural situado en el cascarón absidal se aleja del ubicado en el semicírculo absidal por las mayores pretensiones naturalistas, reflejadas tanto en la manera con que las figuras han sido construidas como en el tratamiento de los pliegues de las vestimentas con que van ataviadas, en la creación de una sensación de espacialidad o en el predominio del color frente al carácter dibujístico o lineal. Sin embargo, no se encuadra aún en el estilo hispanoflamenco, debido a la ausencia de una plasmación minuciosa de una realidad inmediata, aspecto que, aunque se refleja tímidamente en la manera de representar el libro del león de San Marcos, no se llega a concretar, como tampoco el gusto existente por el retrato, especialmente en

${ }^{39}$ GUTIÉRREZ BAÑOS, Fernando, Aportación al estudio de la pintura de estilo gótico lineal en Castilla y León: Precisiones cronológicas y corpus de pintura mural y sobre tabla, t. I, Madrid, Fundación Universitaria Española, 2005, p. 268.

40 ÁLVAREZ MARTíNEZ, María del Rosario, Los instrumentos musicales en la plástica española durante la Edad Medía: los cordófonos, tomo I, Madrid, Editorial de la Universidad Complutense, 1982, p. 639. 
la figura humana, que caracterizará al estilo hispanoflamenco. Por todo ello, pudiera pertenecer a un estilo gótico internacional avanzado, ejecutado entre la década de los sesenta y setenta del siglo XV.

Para finalizar, a pesar de la mayor calidad de las pinturas murales del cascarón absidal, en general esta obra es uno de los muchos ejemplos del creciente proceso de marginalización sufrido por la pintura mural desde finales del siglo XIV, cuando la vanguardia pictórica pasó definitivamente a la pintura sobre tabla, formato donde se aprecia, en el ámbito vallisoletano, obras tan excelsas dentro del estilo internacional, como la Anunciación de Juan de Burgos o el retablo realizado por Nicolás Francés para la capilla del contador Saldaña en el convento de Santa Clara de Tordesillas, cuya comparación con el conjunto mural de la iglesia de San Juan Bautista de Fresno el Viejo no tiene cabida. 